\title{
Política de educação inclusiva: perspectiva de educação especial na gestão 2015 a 2019 da EEEFM 'José Teixeira Fialho'
}

Observa-se que após realização das experiências durante esse período de anos trabalhados com os alunos especiais a educação inclusiva obteve maiores sucessos no processo de ensino aprendizado, quando foram utilizadas diversas metodologias, que por sua vez são relatadas pelos próprios estudantes públicas alvo da educação inclusiva. As metodologias por meio de projetos de ensino foram preponderantes para o crescimento profissional, pois, verificou-se que os materiais concretos revolucionam a aprendizagem dos alunos especiais quando trabalhados de forma orientada sistematicamente e com apoio de todos os profissionais da escola, gestores, alunos, família e comunidade. Os comportamentos dos alunos com deficiências intelectuais e autistas permutaram gradativamente para melhor na comunicação, socialização, linguagem verbal e não verbal, autoestima, criticidade, criatividade, inovação, desenvolvimento sustentável, empreendedorismo, alunos que não apresentavam perspectiva de vida, aparentando pacatos, calados, cabisbaixos, ora agressivos, ora agitados, transformaram repentinamente se tornando falantes, socializados, inovadores, pesquisadores, críticos, bem humorados com os colegas, profissionais da escola e a comunidade. Atualmente, são sonhadores em ganhar seu próprio sustento arav́s de decrescente, sequenciação, produção de discursos, vídeos, relatos, experiências químicas, sensação de calor, terminologia, alimentação saudável, saúde física, mental e social, interatividad dentro e fora da escola e economia. Qualquer escola seja ela municipal estadual ou federal poderá trabalhar com essa metodologia explorando as potencialidades e habilidades dos aluno especiais, o que necessita é de um acompanhamento assíduo intervindo quando necessário para resolver possíveis conflitos entre os estudantes ou entre profissionais de trabalho. Sempre dialogando e solucionando - os de forma unânimes as divergências surgidas visando sempre o bem-estar, aprendizagem sólida, prazerosa, significativa propiciando avanços na educação inclusiva e no ensino regular, em todos os níveis de aprendizagem desde a infância até ao ensino superior. A presente pesquisa pretende apresentar que é possível ter uma Educação Pública de qualidade atendendo de forma quantitativa e qualitativa, quando propomos um trabalho equitativo de atendimento humanizado aos estudantes.

Palavras-chave: Resultados; Equidade; Ética; Inclusão; Humanização.

\section{Inclusive education policy: perspective of special education in the 2015 to 2019 management of EEEFM 'José Teixeira Fialho'}

\begin{abstract}
It is observed that after carrying out the experiences during this period of years worked with special students, inclusive education achieved greater successes in the teaching and learning process, when several methodologies were used, which in turn are reported by the public students targeted by the education inclusive. Methodologies through teaching projects were preponderant for professional growth, as it was found that concrete materials revolutionize the learning of special students when worked in a systematic way and with the support of all school professionals, managers, students, family and community. The behaviors of students with intellectual and autistic disabilities gradually changed for better communication, socialization, verbal and non-verbal language, self-esteem, criticality, creativity, innovation, sustainable development, entrepreneurship, students who did not have a life perspective, looking calm, silent, downcast, sometimes aggressive, sometimes agitated, they suddenly became talkative, socialized, innovative, researchers, critics, good-natured with colleagues, school professionals and the community, Currently, they are dreamers of earning their own living through their skills: They developed motor skills, affectivity, perception, concepts of quantity, quality, distance, laterality, community. Currently, they are dreamers of earning their own living through their skills: They developed motor skills, affectivity, perception, concepts of quantity, quality, distance, laterality,
reuse of materials, conservation of the environment - our habitat, notions of time, space , geographic location, potential, diameter, area, perimeter, quantities, ascending, descending order, reuse of materials, conservation of the environment - our habitat, notions of time, space, geographic location, potential, diameter, area, perimeter, quantities, ascending, descending order,
sequencing, production of speeches, videos, reports, chemical experiments, feeling of warmth, terminology, healthy eating, physical, mental and social health, interactivity within and out of school and economics. Any school, whether state or federal, will be able to work with this methodology, exploring the potential and skills of special students, what is needed is a constan monitoring intervening when necessary to resolve possible conflicts between students or between work professionals. Always dialoguing and resolving them in a unanimous way the divergences arisen aiming at the well-being, solid, pleasurable and significant learning, providing advances in inclusive education and regular education, in all levels of learning from childhood to higher education. The present research intends to present that it is possible to have a quality Public Education serving in a quantitative and qualitative way, when we propose an equitable work of humanized attendance to the students.
\end{abstract}

Keywords: Results; Equity; Ethic; Inclusion; Humanization.

Topic: Gestão e Empreendedorismo no Campo Educacional

Reviewed anonymously in the process of blind peer.
Received: 25/07/2020

Approved: $14 / 11 / 2020$
Jailson Mauricio Pinto (D)

Centro Universitário Leonardo da Vinci, Brasil

http://lattes.cnpq.br/5630364581431753

http://orcid.org/0000-0002-4051-0051

jailsonecop@hotmail.com

Douglas Vicente do Carmo Lima

Universidade Federal do Espírito Santo, Brasil

http://lattes.cnpq.br/8496236068852285

biologia14vicente@gmail.com

Ivani Vieira Damaceno (iD)

Universidade Federal do Espírito Santo, Brasil

http://lattes.cnpq.br/7230901191155082

http://orcid.org/0000-0002-7140-7241

ivanivida@gmail.com.br
Renilza Moura Falquete Cardoso

Universidade Federal do Espírito Santo, Brasil

http://lattes.cnpq.br/4001818040498285

renilza.falquete@hotmail.com
Referencing this:

PINTO, J. M.; LIMA, D. V. C.; DAMACENO, I. V.; CARDOSO, R. M. F.. Política de educação inclusiva: perspectiva de educação especial na gestão 2015 a 2019 da EEEFM 'José Teixeira Fialho'. Humanum Sciences, v.2, n.2, p.40-55, 2020. DOI: http://doi.org/10.6008/CBPC2674-6654.2020.002.0004 


\section{INTRODUÇÃO}

A Educação Especial na EEEFM 'José Teixeira Fialho' no ano de dois mil e quatorze contava com sete estudantes, atendimento de uma professora com carga horária de vinte e cinco horas semanais. Esse atendimento funcionava no contraturno, a gestão apoiava esse trabalho com o AEE, os estudantes tinham uma boa interação com gestão, professores, todavia muitos destes eram resistentes ao trabalho adaptado às necessidades especiais dos estudantes público alvo da Educação Especial.

Portanto, alguns aprendizes ficavam reprovados em consequência de suas deficiências, pois não acompanhavam os níveis das turmas. Não havia uma assessoria por parte da equipe gestora escolar no contexto da Educação Especial na perspectiva da Educação Inclusiva, colocando esses estudantes como alvos de ações diferenciadas, que dessem para os mesmos ter um aprendizado significativo, diminuindo o número de reprovações no contexto escolar.

Em dois mil e quinze a Instituição passou a atender vinte e dois estudantes. Esses números tiveram esse salto devido ao apoio aos familiares com conversas e dizendo as famílias que procurassem além do apoio escolar, um especialista na área da saúde para que pudesse dar maiores orientações. A ação social realizada pela Secretaria de Assistência Social da Prefeitura do Município de Ecoporanga ajudou nessa ação. Se seguir temos o quadro totalizador da Escola onde podemos observar a quantidade de estudantes que ficaram retidos, sendo a maioria estudantes público alvo da Educação Especial. Isso porque ‘Dez anos depois da assinatura da declaração de Salamanca, que garante aos portadores de necessidades especiais o direito de frequentar o ensino regular, ainda é pequeno o número de escolas brasileiras em condições de acolher esses alunos'. Mesmo após a declaração de Salamanca, que prega a educação inclusiva. A educação vem sofrendo porque não há uma qualificação nas escolas e educadores para receber estas pessoas. Porque a educação modifica-se de forma acelerada.

Na EEEFM 'José Teixeira Fialho' foi construído rampas, banheiros adaptados, aquisição de materiais didáticos que ajudem na educação Inclusiva e isso trouxe resultados de qualidade.

A presente pesquisa pretende apresentar que é possível ter uma Educação Pública de qualidade atendendo de forma quantitativa e qualitativa aos estudantes, quando propomos um trabalho equitativo de atendimento humanizado aos estudantes.

\section{REVISÃO TEÓRICA}

De acordo com Graciani (2001) os princípios contidos na concepção da educação em que as tradições da realidade na qual se insere a prática educativa, tais como produção e construção do conhecimento, a luta por uma educação emancipadora, a defesa de uma educação como prática de liberdade e como precondição de vida democrática, pela relação dialógica de um planejamento comunitário e participativo, induziram milhares de educadores populares a repensarem sua prática, a redefini-la e a redimensioná-la mediante o compromisso de um projeto político-pedagógico que se contrapõe à educação do colonizador e que seja capaz de reverter à realidade de opressão e dominação dos vários segmentos populares. 
Cada momento da aprendizagem representa uma possibilidade aberta pelos momentos anteriormente vividos pelo aprendiz, que é condição indispensável da formação dos momentos seguintes, só sendo possível pela ação do sujeito sobre o objeto e pela interação social. Aprender, para Perrenoud (2001) significa:

[...] uma atividade complexa, frágil, que mobiliza a imagem de si mesmo, o fantasma, a confiança, a criatividade, o gosto pelo riso e pela exploração, a angústia, o desejo, a identidade, aspectos fundamentais no âmbito pessoal e cultural.

Portanto, a aprendizagem depende da articulação de fatores internos e externos ao sujeito. Sendo que os fatores internos se referem ao funcionamento do corpo como um instrumento responsável pelos atos ou gestos automáticos e os externos são aqueles que dependem das condições do meio que cerca o indivíduo sendo estes os responsáveis por gerar grande parte das condições necessárias para o aluno aprender.

A aprendizagem deve resultar do interesse próprio do aluno quando compreende que o conhecimento é indispensável para o sucesso. Neste sentido Perrenoud (2001) afirma:

As novas tecnologias valorizam o conhecimento como recurso positivo, do qual o indivíduo deve apropriar-se em seu próprio interesse. Para aprender 'dignamente', é preciso ter vontade de dominar um saber, aprender com prazer. Nesse espírito, o trabalho de aprendizagem deve proceder de um projeto e de interesses pessoais. Também nesse caso, a intenção é libertadora. Contudo, as novas pedagogias fazem pesar fortes expectativas sobre os alunos quando desqualificam toda relação burocrática com o saber, toda aprendizagem motivada exclusivamente pelo medo das sanções, pela atração das recompensas ou pelo simples conformismo. As novas pedagogias privam de toda legitimidade os alunos que gostariam de aprender apenas para agradar aos outros ou para obter benefícios sociais. Eles devem querer aprender por si mesmos, porque compreenderam que a aprendizagem não é apenas útil na vida, mas uma forma privilegiada de realização.

As novas pedagogias são fortemente centradas na criança como pessoa única, ativa, criativa e responsável. Elas não dão totalmente as costas à noção de trabalho, de esforço, de limite, mas dão muita importância ao prazer de fazer e aprender, a atividade funcional. Dessa forma a criança vai à escola sem angústia, com prazer. Os professores que aderem à essa pedagogia às vezes se opõem a seleção escolar em todas as suas formas, principalmente as notas que hierarquizam seus alunos e à repetência. Preferem uma organização flexível, pouco codificada, diferenciada, flutuante, negociada em cada caso, ou seja, difícil de delimitar. No entanto, exige muito dos alunos, porque os coloca constantemente em situação de parceiros, de interlocutores responsáveis, que devem motivar e negociar suas escolhas, retirando-lhes o conforto de uma relação estratégica à instituição, obrigando-os a participar, a se envolver, a se identificar com o andamento do conjunto.

O educador deve estabelecer estratégias de ensino no seu processo de planejamento. Exige manterse atento e crítico, para que esse seja flexível, suprindo as necessidades individuais de cada aluno. Porém nem todos estão atentos ao processo de flexibilidade, e continuam uniformizando-o. Nessa linha de pensamento Perrenoud (2001) relata:

Toda situação didática proposta ou imposta uniformemente a um grupo de alunos é inadequada para uma parcela deles. Para alguns, pode ser dominada facilmente e, por isso, constitui um desafio e provoca aprendizagem. Outros, porém não conseguem entender a tarefa e, por isso, não se envolvem nela. 
Diversos fatores contribuem para que o aluno não se envolva nas atividades propostas pelos educadores, tarefas que fogem da realidade da criança, que não instigam a curiosidade dela, professores com má qualificação, faltam de respeito com as diferenças, falta de apoio familiar, etc., fatores que não as leva a se sentirem parte integrante deste processo de aprendizagem. Este entre outros, são fatores que contribuem para o não aprender.

\section{Possíveis dificuldades dos alunos}

Alguns sintomas como o aborrecimento, a tristeza, o medo e a ansiedade podem dificultar ou deter completamente as etapas do aprendizado. As medidas disciplinares devem ser tomadas no momento adequado, para que o processo de aprendizagem seja eficaz. Ao falar sobre as dificuldades de aprender Chabanne (2006) alerta:

As 'dificuldades escolares' não devem ser encaradas como coisas em si ou patologias: só podem ser mencionadas eventualmente como sintomas, que lembram e revelam o comportamento de uma pessoa, num momento determinado e num contexto singular.

A dificuldade escolar não deve ser considerada como um problema definitivo, pois é um momento do trabalho escolar, que visa o sucesso. Todo exercício apresenta dificuldades, sempre há um momento que o aluno é posto à prova quanto à sua memória, a sua inteligência, sua capacidade de interpretar um enunciado, de buscar soluções, de procurar novos caminhos para assim alcançar o sucesso. Talvez o período que está com dificuldade é um tempo de experiência que o aluno vive e interpreta e assim a dificuldade escolar se torna uma experiência.

As dificuldades são representadas por diversos sintomas, que não se explicam por si próprias, e não devem ser consideradas como título de incompetência e sim resultam de movimentos internos do próprio indivíduo. $\mathrm{O}$ aluno está inserido numa realidade de lutas e indecisões onde ao mesmo tempo em que deseja realizar os seus sonhos, se depara com regras escolares, com exigências da sociedade que requer a sua integração, como também a definição da imagem atual e a que gostaria de ter.

Portanto as dificuldades escolares fazem parte da vida do indivíduo e do crescimento dessas lutas. As dificuldades variam e são superadas de acordo com o grau de cada uma delas, como também da capacidade de cada pessoa em resolver os problemas, que quando não resolvidos podem manifestar regressões e quando superados o ajuda a investir na construção de um futuro melhor.

\section{Alunos de camadas populares e do meio rural}

Ao falar sobre os alunos das camadas populares, Ceccon et al. (1998) dizem que:

De fato, são sobretudo as crianças provenientes das camadas populares e do meio rural que fracassam na escola e são forçadas a interromper seus estudos. Evidentemente, essas crianças constituem a grande maioria da população de nosso país e são elas, justamente, as que mais precisam da escola para poder melhorar de vida. São os pais das crianças que fracassam os que fizeram mais sacrifícios para que seus filhos pudessem estudar. Foram eles que lutaram e, por vezes, esperaram anos até conseguir vaga para matricular seus filhos. Foram eles que passaram dificuldades para comprar cadernos e uniformes. Foram eles que sofreram ao ver seus filhos serem reprovados e obrigados a repetir o ano. $E$, no entanto, todo esse esforço, todos esses sacrifícios, toda essa esperança não serviu de nada. 
Na verdade, as crianças das camadas populares e da zona rural convivem diariamente com problemas que afetam o emocional e o intelectual das mesmas. Elas vão para a escola mal alimentadas, muitas vezes revoltadas por não terem o que os colegas de classe mais favorecida têm. Convivem com a dificuldade financeira dos pais, não possuem recursos tecnológicos e didáticos suficientes, muitos começam a trabalhar muito cedo, para ajudarem na renda familiar, sendo obrigadas a abandonarem as salas de aulas e por diversas vezes não são bem recebidas nas escolas. Diante de todos os problemas elas não têm ânimo para estudar e ainda são apontadas como um grupo contribuinte para o fracasso escolar.

\section{Como se constrói fracassos e sucessos na visão de Perrenoud}

Perrenoud (2001) também fala da tríplice fabricação do fracasso. "Primeiro: Currículo; Segundo: Problema da indiferença às diferenças; e terceiro: Modo e o momento da avaliação. Essa é uma forma de fabricar sucessos e fracassos".

O problema do fracasso fortemente presente no sistema educacional, não se dá somente pela atuação dos profissionais, nem pela forma quantitativa de avaliar. Assim como não se constrói uma realidade de sucesso apenas na tentativa de superar as desigualdades de classes, pois o fracasso tem-se infiltrado nas escolas ao longo dos anos, tornando-o mais forte, desafiando os profissionais da educação.

\section{Avaliação em sala de aula}

O meio educacional vive um momento de reconstrução de propostas acerca de novas formas de trabalho escolar, podendo perceber que a avaliação representa uma questão importante neste processo.

De acordo com Esteban (2003) é preciso uma nova forma de avaliar:

O processo de avaliação do resultado escolar dos alunos e alunas está profundamente marcado pela necessidade de criação de uma nova cultura sobre avaliação, que ultrapasse os limites da técnica e incorpore em sua dinâmica a dimensão ética.

Mesmo a avaliação sendo uma prática presente no processo de ensino, a ação avaliativa ainda é um tema em discussão. Há uma intensa crítica aos procedimentos e instrumentos de avaliação frequentemente usados na sala de aula, que muitas vezes se fazem acompanhar da ideia de novas diretrizes ou de novas propostas de ação. $\mathrm{O}$ olhar para essas novas alternativas precisa estar atento aos discursos e as práticas para evitar que a visão técnica continue encobrindo a visão ética.

O aluno perde o interesse em aprender quando o conhecimento é reduzido à forma quantitativa de avaliar. Neste sentido Garcia (2003) afirma:

O prazer de aprender desaparece quando a aprendizagem é reduzida a provas e notas; os alunos passam a estudar 'para se dar bem na prova' e para isso têm de memorizar as respostas consideradas certas pelo professor ou professora. Desaparecem o debate, a polêmica, as diferentes leituras do mesmo texto, o exercício da dúvida e do pensamento divergente, a pluralidade. A sala de aula se torna um pobre espaço de repetição, sem possibilidade de criação e circulação de novas ideias.

\section{MATERIAIS E MÉTODOS}

A presente pesquisa foi realizada na Escola Estadual de Ensino Fundamental e Médio (EEFM) José 
Teixeira Fialho, localizada no Distrito de Imburana, Ecoporanga-ES. Para atingir os objetivos propostos. Foi realizada uma pesquisa de campo, reunindo e comparando os diferentes dados obtidos de forma qualitativa e quantitativa listando os principais fatores que permitem aos estudantes público alvo da Educação Especial apresentar suas potencialidades e a desenvolver suas competências, bem como suas habilidades no contexto escolar.

A pesquisa durou de 2014 a 2019, onde cada avanço obtido pelos estudantes será apresentado no decorrer de cada ano letivo. As ações aqui apresentadas foram evidenciadas pela prática docente no cotidiano escolar, enfatizando a importância da gestão escolar estar apoiando essas especificidades encontradas no contexto escolar e que precisam de atenção para que as políticas públicas sejam de fato implantadas para aqueles que mais precisam. A seguir, será abordado cada ano letivo e os avanços obtidos pela Educação Especial.

\section{Educação especial e seus avanços no contexto da educação inclusiva no ano de dois mil e quinze, na EEEFM 'José Teixeira Fialho'}

Em dois mil e quinze, no início do ano letivo, houve substituição da dupla gestora da escola (Diretor e pedagogo) colaborando com mudanças significativas nas ações junto a Educação Especial. Foram colocadas ações que previam o Projeto Político Pedagógico da Escola em prática. A equipe gestora da escola fez um estudo da Legislação vigente referente aos estudantes público alvo da Educação Especial e após, foi apresentado o estudo aos demais integrantes da equipe pedagógica da escola durante os encontros semanais para planejamento por área de conhecimento.

Durante os Conselhos de classe houve espaço para que a professora que trabalhava com a temática pudesse apresentar as fragilidades e potencialidades dos estudantes do Atendimento Educacional especializado (AEE). Isso trouxe um ambiente propício para discussão e novos rumos da Educação Especial no Contexto da Inclusão dos estudantes portadores de deficiências na sala comum.

Nessa nova vertente, a Educação na perspectiva da Educação Inclusiva expandiu. A equipe gestora da escola fez um excelente trabalho de parcerias com as famílias dos alunos especiais, reuniões no decorrer do ano, e esse trabalho veio corroborando com o avanço da educação inclusiva na escola. Os pais eram informados sobre as necessidades especiais de seus filhos com diálogos abertos, as leis da educação inclusiva eram transmitidas para eles juntamente com seus filhos. Eles foram entendendo a diferença de uma pessoa deficiente mental e um doente mental, assim as famílias procuraram com maiores facilidades e aceitabilidade os profissionais especializados para os tratamentos de seus filhos, e houve bastantes melhorias em níveis de aprendizados. Além disso, através da gestão da escola, os profissionais da mesma foram informados em Conselhos de Classe, reuniões de Jornadas de Planejamentos Pedagógicos (JPP) sobre as leis vigentes da educação especial. 
Educação especial e seus avanços no contexto da educação inclusiva no ano de dois mil e dezesseis, na EEEFM ‘José Teixeira Fialho’

No ano de 2016 o número de estudantes público alvo da educação especial foi para 31 estudantes. Nesse ano, os discentes iniciaram um trabalho com projetos com aprovação da gestão escolar cumprindo a legislação da Política Nacional de Educação Especial na Perspectiva da Educação Inclusiva, de 2008, o trabalho concreto, as parcerias com o ensino regular em desenvolver atividades diferenciadas que promovam o interesse, motivação, permanência dos alunos na escola objetivando um ensino inclusivo real e parcerias com os serviços intersetoriais (saúde e serviço social) conforme determina a lei supracitada.
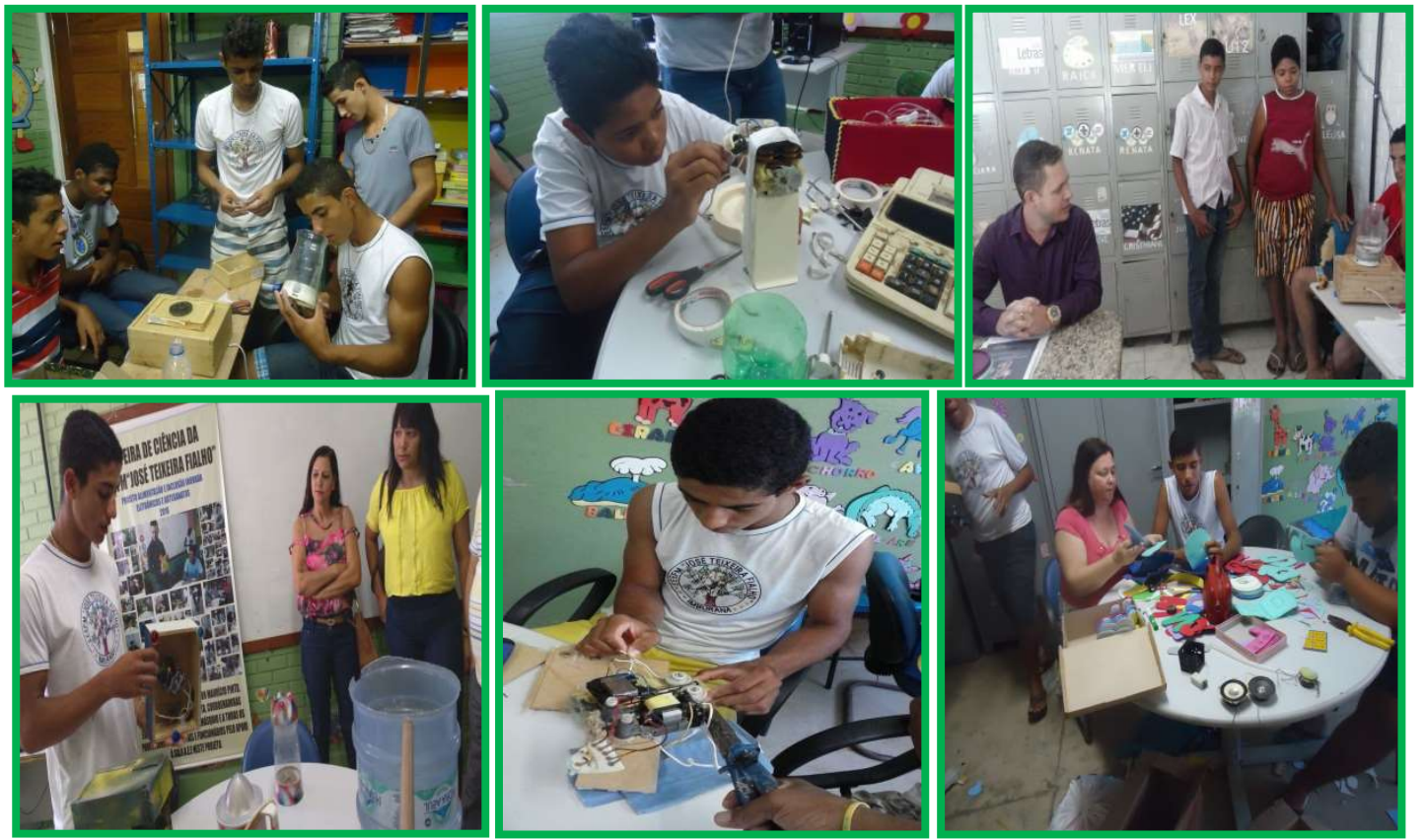

Figura 1: Imagens de estudantes trabalhando com materiais concretos em parceria com o ensino regular.

Percebe-se de forma nítida um trabalho de inclusão onde os alunos do ensino regular mostram equidade junto aos alunos especiais, não discriminam entre si, aceitam os mesmos com respeito às necessidades destes educandos. Nota-se que a prática pedagógica tradicional, baseada apenas na transmissão de conhecimento, é ineficaz para ensinar a maioria dos alunos. A escola, tradicionalmente, apresentava sua atenção em satisfazer necessidades comuns, cumprimentos de currículo, delineando objetivos sem considerar as características específicas de cada aluno. Essa postura tradicional, no âmbito curricular, é demonstrada por propostas rígidas que desconsideram os diversos contextos nos quais ocorrem os processos de ensino e aprendizagem.

É preciso conhecer as diversas realidades, para a execução de um currículo que seja interativo, como aborda Ferraço (2008):

Se quisermos uma 'escola para todos' temos de reconhecer e conhecer as especificidades de cada contexto e de cada situação, os silêncios e as marginalizações. Este reconhecimento, do ponto de vista do exercício profissional, exige uma contínua procura dos 'caminhos' e processos que sejam os mais adequados para cada situação, o que significa que exige uma intervenção ativa e crítica nos processos sociais e de configuração curricular.

Como consequência, é possível observar a alta ocorrência de dificuldades de aprendizagem, repetências, evasão e fracasso escolar. O movimento de inclusão escolar revela que a educação, com seus 
métodos tradicionais, exclui cada vez mais alunos, ao invés de incluí-los. Assim sendo, foi evidenciado que considerar as especificidades de cada estudante é fundamental para garantir a qualidade de ensino para todos e não apenas para aqueles que apresentam dificuldades mais evidentes.

Os estudantes apresentam características físicas, comportamentais e emocionais próprias, a escola observou que devido à existência de tais características, uma prática de ensino voltada para um conjunto homogêneo de discentes não alcança bom êxito. Há necessidade de o professor traçar e executar estratégias de ensino utilizadas de maneira adaptada às características dos estudantes, à composição da classe e a história das relações entre os educandos, entre eles e o professor.

É preponderante que cada professor permute sua prática pedagógica obedecendo às normas da Educação Especial, está escola procura trabalhar em harmonia com essas leis. A gestão escolar transmite e efetua alinhamento junto aos educadores para que façam as adaptações necessárias dos conteúdos a serem trabalhados em salas de aulas.

No ano de 2016 a escola tornou referência no Ensino da Educação Inclusiva conforme matéria exibida em um blog: 'Escola José Teixeira Fialho torna-se referência na região no trabalho com alunos autistas'1.

\section{Educação especial e seus avanços no contexto da educação inclusiva em dois mil e dezessete, na EEEFM 'José Teixeira Fialho'}

Em 2017 havia vinte e nove estudantes, duas professoras com quarenta horas cada uma, para que pudessem continuar com o trabalho de inclusão. O AEE em parcerias com o ensino regular, serviços intersetorias, famílias, os estudantes realizavam projetos com essas parcerias atendiam os alunos deficientes mentais, Transtornos Globais de Desenvolvimento, autismo infantil, Síndrome de Asperger e de WilliamsBeuren.

É nítido que os Transtornos Globais do Desenvolvimento também causam variações na atenção, na concentração e, eventualmente, na coordenação motora. Mudanças de humor sem causa aparente e acessos de agressividade comuns em alguns casos. Os estudantes apresentam seus interesses de maneira diferenciada e podem fixar sua atenção em uma só atividade, como observar determinados objetos, por exemplo. Nesta escola temos esse público-alvo, os alunos possuem comportamentos variados em dias diversos, muitos agitados e conseguem se concentrarem melhor quando realizam atividades que desenvolvam sua coordenação motora, raciocínios lógicos, comunicação escrita e oral, produções de textos, oralidade, esse trabalho com os materiais concretos facilita o envolvimento, o ensino e a aprendizagem dos estudantes.

A Direção escolar fomentava o trabalho com projetos eletrônicos e houve avanços na aprendizagem e permanência desses estudantes na escola. As crianças ou adolescentes com transtornos de desenvolvimento apresentam diferenças e merecem atenção com relação às áreas de interação social, comunicação e comportamento. Na escola, mesmo com tempos diferentes de aprendizagem, esses alunos são incluídos em classes com os pares da mesma faixa etária, estabelecendo rotinas em grupo e auxiliando o

\footnotetext{
${ }^{1}$ https://universo-informativo1.webnode.com/l/escola-jose-teixeira-fialho-torna-se-referencia-na-regiao-no-trabalho-com-alunos-autistas/ 
aluno a incorporar regras de convívio social, que são atitudes de extrema importância para garantir o desenvolvimento na escola.

São apresentadas as atividades do currículo visualmente que é outra ação que ajudou no processo de aprendizagem desses alunos, realização de ajustes nas atividades sempre que necessário e conta-se com a ajuda do profissional responsável pelo Atendimento Educacional Especializado (AEE). Cabendo ao professor identificar as potências dos alunos e investir em ações positivas, estimular a autonomia e fazer o trabalho de conquista e confiança da criança ou adolescente. A inclusão de estudantes com deficiência, que apresentam necessidades educacionais especiais na sala de aula comum do ensino regular, esclareceu que a prática pedagógica tradicional, baseada apenas na transmissão de conhecimento, é ineficaz para ensinar a maioria dos alunos.

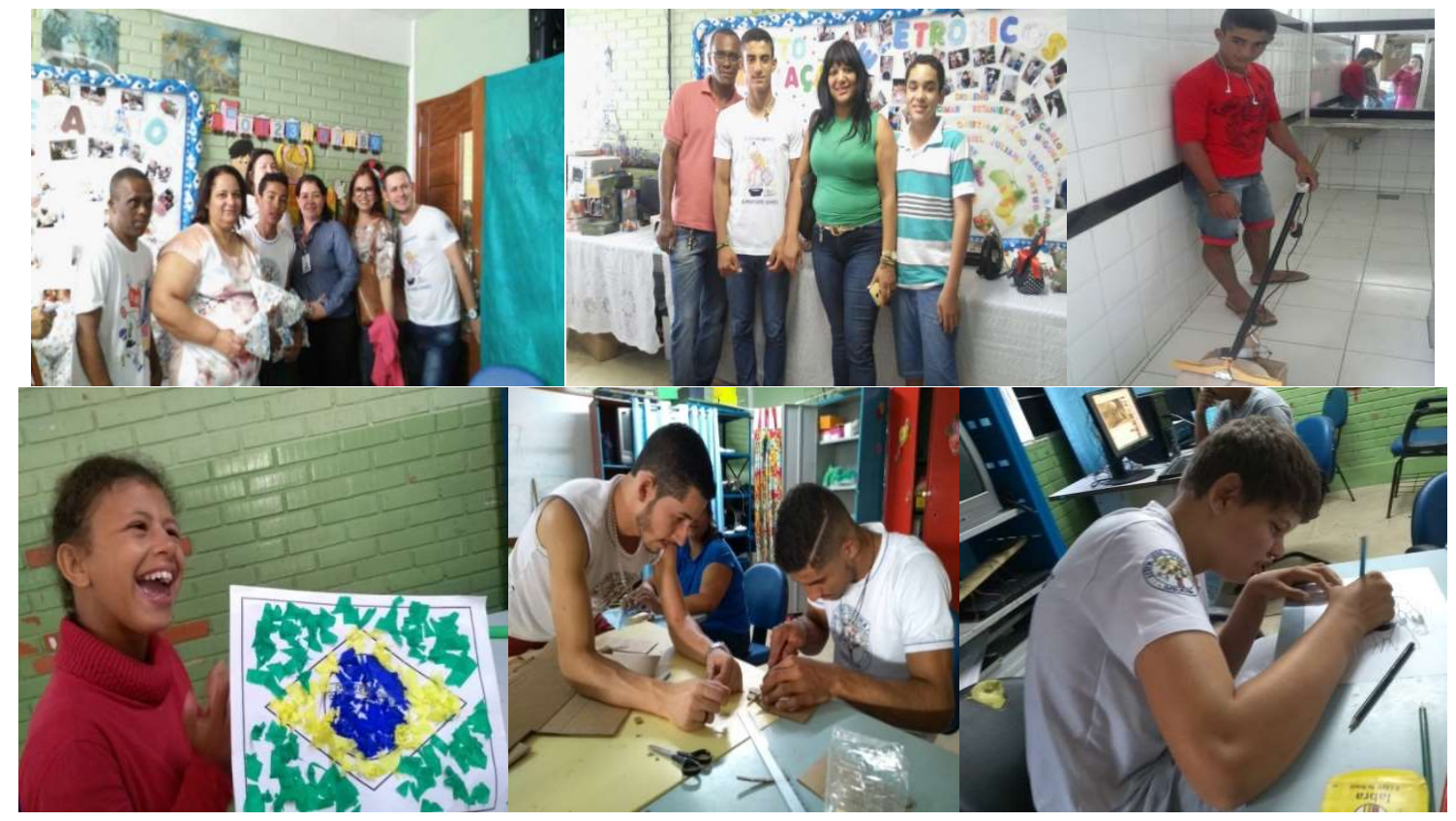

Figura 2: Imagem de projetos eletrônicos com Ensino Fundamental séries finais e Ensino Médio.

Educação especial e seus avanços no contexto da educação inclusiva no ano de dois mil e dezoito na EEEFM 'José Teixeira Fialho'

Em dois mil e dezoito havia trinta e oito estudantes e duas professoras de quarenta horas semanais cada. Esse trabalho continuou com parcerias com o ensino regular, saúde, assistência social, Associação de pais e amigos dos autistas de Barra de São Francisco - ES, os alunos realizavam atividades com materiais concretos e os professores avaliavam esses estudantes por meio das atividades realizadas em parcerias com a sala do AEE. Foram confeccionados diversos objetos utilizando materiais eletrônicos. Os estudantes público alvo da Educação Especial, a maioria possui habilidades em trabalhar com meios eletrônicos como: motores de liquidificadores, micro-ondas, tanquinhos e máquinas de lavar roupas, DVDs, batedeiras, outros produzindo novas peças úteis utilizando materiais recicláveis conforme imagens a seguir: Construção do jogo Computer Game da disciplina de inglês - Circuito elétrico construído pelos alunos da 1a série do EM no ano de dois mil e dezoito. E experiências realizadas com o Ensino Fundamental séries iniciais. Diversos outros projetos executados com êxitos na Instituição escolar com o AEE. 


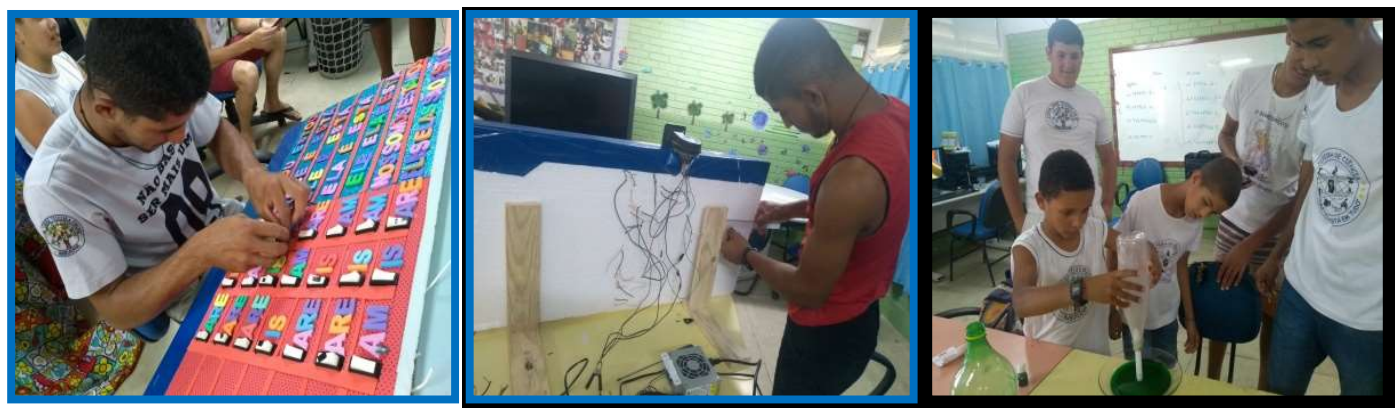

Figura 3: Imagens projeto EF2 e EM e experiências com o Ensino Fundamental 1.

Esta escola procura cumprir com os princípios contidos na LDB 9394/1996 (Lei Diretrizes e Bases da Educação) e no Plano Nacional de Educação que determinam que a escola se mobilize para estruturar um conjunto de ações e providenciar recursos necessários que garantam o acesso e a permanência de todos os alunos, promovendo um ensino que respeite as especificidades da aprendizagem de cada um legalmente nos Parâmetros Curriculares Nacionais: Adaptações Curriculares, conforme anunciado anteriormente (MEC, 2009).

Mas, o que são adaptações curriculares? As adaptações curriculares implicam a planificação pedagógica e as ações docentes fundamentadas em critérios que definem o que o estudante deve aprender; como e quando aprender; que formas de organização do ensino são mais eficientes para o processo de aprendizagem; como e quando avaliar o aluno. A terminologia adaptação, pode ser interpretada como flexibilização, uma vez que pressupõe a existência de alterações e/ou modificações no processo educacional, essencialmente no âmbito curricular. Para isso o currículo escolar deve ser tomado como referência na identificação de possíveis alterações em função de necessidades especiais dos alunos.

Em síntese, a unidade escolar deve adotar a mesma proposta curricular para todos os estudantes, e, realizar adaptações, alterações para os estudantes deficientes que são inclusos no contexto escolar, observando às especificidades de cada educando. Cabe à equipe técnica pedagógica, com aprovação do gestor da escola incluindo o professor da sala comum, realizar o mapeamento das particularidades educacionais da demanda educacional que necessita de ajustes no currículo e propor o manejo das condições adequadas juntamente com o professor da educação especial.

Para realizar a adaptação curricular é necessário que o projeto pedagógico da escola e o planejamento de ensino devem considerar objetivos educacionais e estratégias didático-pedagógicas que garantam acessibilidade de todos os alunos na rede escolar. Construir uma escola inclusiva exigirá esforços de toda a comunidade escolar no âmbito político, administrativo e pedagógico, envolvendo mudanças nos níveis: Arquitetônico (eliminação ou desobstrução de barreiras ambientais); Atitudinal (prevenção e eliminação de preconceitos, estereótipos, estigmas e quaisquer discriminações); Comunicacional (adequação de código e sinais); Metodológico (adequação e flexibilização de técnicas e teorias, abordagens e métodos pedagógicos); Instrumental (adaptação de aparelhos, materiais, recursos e equipamentos pedagógicos); Pragmáticos (eliminação de barreiras invisíveis nas políticas e no amparo legal vigente). Além dos aspectos mencionados, cabe ainda ressaltar a importância de projetos ou propostas que garantam a formação continuada de todos os que trabalham na comunidade escolar. 
A intervenção pedagógica numa perspectiva inclusiva deverá considerar que a diversidade está presente em sala de aula e que as diferentes formas de aprender enriquecem o processo educacional. Nela o professor educador assume grande responsabilidade na superação de barreiras de atitudes discriminatórias em relação às diferenças dentro da escola.

No seu estabelecimento maneiras diversificadas de organizar o tempo e o espaço pedagógicos precisam ser previstos para o sucesso escolar, respeitando os estilos e ritmos de aprendizagem e planejando estratégias e recursos utilizados, adequando-os às necessidades dos alunos. O professor, então, na postura de mediador da construção de conhecimentos, deve se preocupar com quem aprende como aprende, com o porquê de estar trabalhando determinado conhecimento e, sobretudo, com a reflexão constante sobre o que está sendo discutido, dando abertura para a manifestação dos posicionamentos e ideias, contrário à sua ou não.

No cotidiano educacional os estudantes que, por dificuldades orgânicas, sociais e/ou culturais, apresentarem defasagem significativa em duas ou mais áreas curriculares, por exemplo, português e matemática, além de estarem também defasados em pelo menos dois anos em relação à idade e série, devem ser avaliados pelo professor e possivelmente necessitarão de ajustes no seu currículo. Então, faz-se importante, primeiramente identificar o que o aluno deveria aprender na série - ou seja, o que é proposto em conteúdos curriculares para a série ou etapa. A partir desse referencial é que se deve identificar o que o aluno já sabe fazer sozinho, o que ele sabe fazer com ajuda e ele ainda não é capaz de aprender.

Para organizar as metodologias favoráveis com o seu ritmo de aprendizagem. Cada caso deve ser analisado em particular, para depois averiguar sobre a necessidade de um currículo adaptado para esse aluno. $\mathrm{O}$ foco do professor/avaliador deverá ser em investigar além das competências ou habilidades que a criança ou adolescente já domina quais eles poderão desenvolver. Observar toda e qualquer manifestação, comportamento e desempenho do aluno, poderá identificar suas necessidades no contexto escolar, deverá envolver todos os profissionais da escola, que direta ou indiretamente atuam com o aluno, tendo como objetivo o estabelecimento de uma proposta pedagógica e a implementação de atividades a serem desenvolvidas, durante o processo de ensino e aprendizagem que estejam em consonância com as necessidades educacionais especiais do aluno com deficiência. Como com qualquer outro aluno é importante que o professor identifique no cotidiano educacional: Se ele compreende e participada de todas as atividades propostas em sala de aula; Se ele apresenta desenvolvimento satisfatório no cumprimento das atividades; Qual é o ritmo de sua aprendizagem diante dos mais diversos conteúdos curriculares - sua aprendizagem é lenta, normal ou rápida; Se apresenta motivado para realizar as atividades propostas intra e extraclasse; Se necessita de recursos adicionais, como auxílio de materiais concretos para resolver o proposto; Se solicita auxílio do colega ou do professor para as atividades; A interação com os colegas dentro e fora de sala de aula; A interação do aluno e com professor e com os demais profissionais da escola; Se consegue se agrupar com os demais alunos em classe e nos outros espaços da escola; Se é assíduo; Se necessita de auxílio para vir à escola; Se cuida dos seus materiais, se tem dificuldades em cumprir regras; Quais são as suas atividades preferidas; O que apresenta facilidade para resolver; Se consegue relatar um fato ocorrido sequencialmente. 
Sendo assim, são inúmeras as observações a serem feitas para que se possa avaliar o aluno com deficiência mental e propor as adaptações curriculares necessárias para o acesso ao currículo comum. Através da gestão escolar a escola oferece a alimentação de forma integral desde o ano de dois mil e dezesseis. Ou seja, merendam por volta das nove horas e quarenta e cinco minutos da manhã, almoçam por volta de meio dia e merendam por volta de quinze horas e quarenta e cinco minutos. Os estudantes possuem nutricionista que faz o cardápio diferenciado deles do ensino regular, as oportunidades de aprendizagem são amplas na escola, o atendimento no AEE é realizado no contraturno, a professora apresenta os documentos necessários para funcionamento das salas com PDIs, plano de aula semanal, pautas de cada sala de aula, relatórios pedagógicos realizados, plano de atendimento anual, todos estes documentos estão na escola comprovando um ensino inclusivo qualificado. Pensamento de Schain (2002), ao falar sobre distúrbios de aprendizagem:

A maioria dos pesquisadores que estudaram o ambiente emocional de crianças com distúrbios de aprendizagem 'constataram a elevada prevalência de problemas familiares.

[...] É evidente que uma criança ansiosa e atemorizada, ou que não consegue se concentrar devido a um ambiente doméstico caótico, terá frustrados seus esforços de adaptação ao meio escolar. As falhas iniciais terão como consequência uma inibição da motivação para novas aquisições... A situação familiar é o principal fator na determinação do estado psíquico da criança que vai para a escola. (SCHAIN, 2002)

\section{Educação especial e seus avanços no contexto da educação inclusiva no ano de dois mil e dezenove na EEEFM 'José Teixeira Fialho'}

No ano de dois mil e dezenove a equipe escolar trabalhou com três professoras do AEE sendo duas com quarenta horas semanais e uma professora de vinte e cinco horas semanais, com um total de trinta e nove estudantes. A relação interpessoal dos alunos especiais varia entre pessoas, onde existem maiores afinidades eles relacionam melhor, os alunos amam trabalhar com materiais concretos, projetos que envolvam a participação deles, os professores trabalham com esses projetos e fazem conexão com os conteúdos ministrados em sala de aula oportunizando aos alunos deficientes a desenvolver o raciocínio lógico, crítico, espírito investigativo, leitura, escrita, percepção, tecnologias, dentre outros.

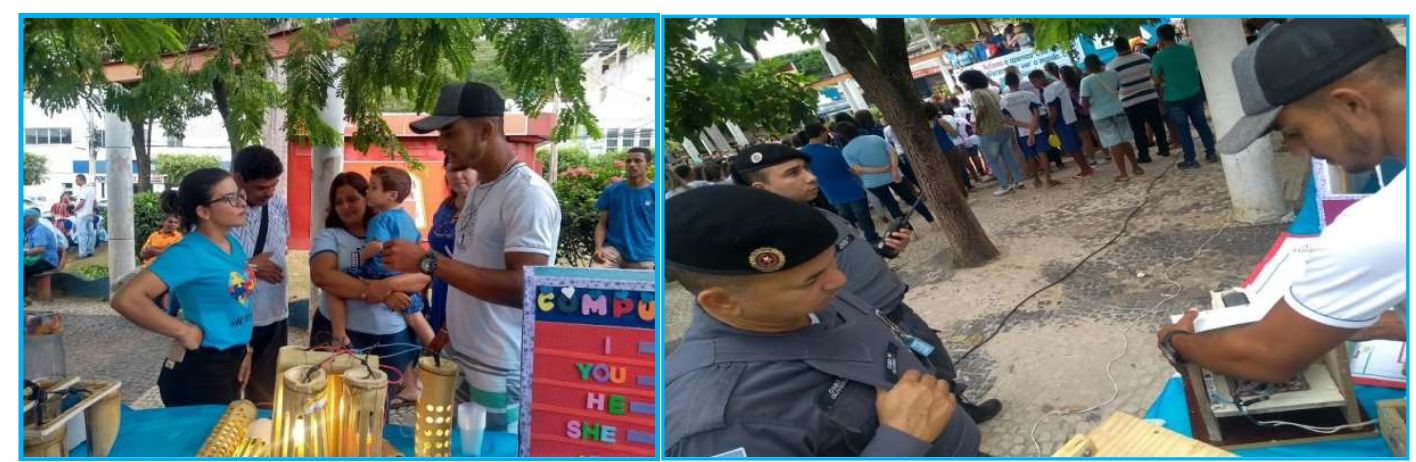

Figura 4: Explicação em praça pública pelo aluno Alcimar Gomes de Souza, 2ª série do EM, objetos construídos pelos alunos do AEE desta escola - Luminárias feitas de bambu, ralador de milho construído com motor de tanquinho de lavar roupas. 


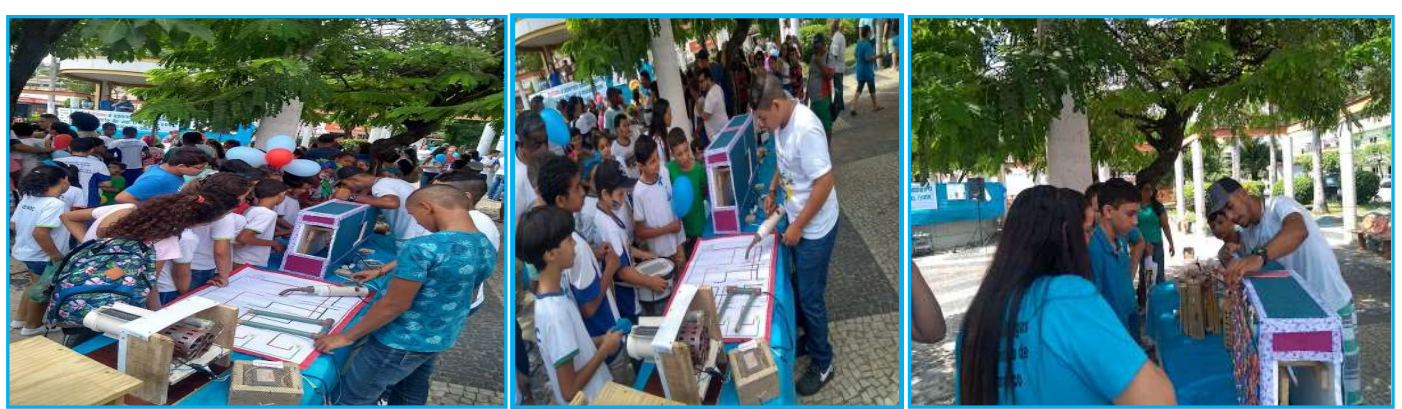

Figura 5: Explicação em praça pública pelos alunos Alcimar Gomes de Souza, 2ª série do EM, Húdson Júnior Pessoa Rocha, Arnir Rodrigues Sheneider do 8 o ano EF, objetos construídos pelos alunos do AEE desta escola - Luminárias feitas de bambu, ralador de milho construído com motor de tanquinho de lavar roupas.

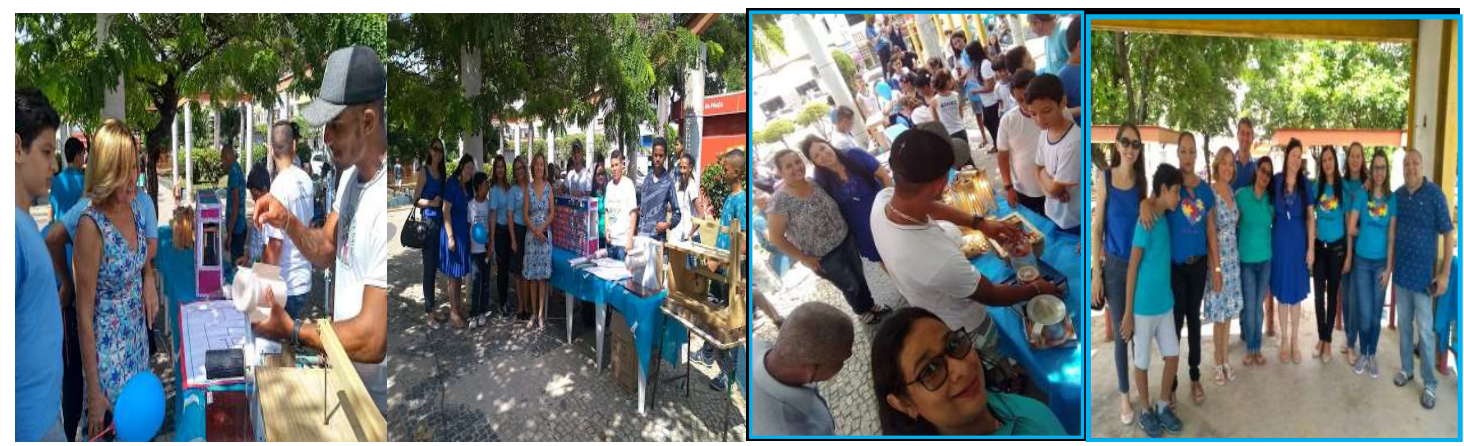

Figura 6: Explicação dos objetos eletrônicos a autora do Projeto de lei vereadora Zirene Surdini Valli é a autora do Projeto de Lei N 3 /2019 e Organizadores do evento: Presidente da Associação de Pais e Amigos do Autista (Márcia Brito de Oliveira), Sandra Ferreira Gambert Secretaria Municipal de Educação e da Câmara Municipal de Vereadores de Barra de São Francisco - ES.

A escola trabalha sempre procurando cumprir a Legislação vigente da Educação Especial (MEC/SECADI Política Nacional de Educação Especial na Perspectiva da Educação Inclusiva, 2008). A Lei de Diretrizes e Bases da Educação Nacional, Lei no 9.394/96, no artigo 59, onde preconiza que os sistemas de ensino devem assegurar aos estudantes currículo, métodos, recursos e organização específicos para atender às suas necessidades; assegura a terminalidade específica àqueles que não atingiram o nível exigido para a conclusão do ensino fundamental, em virtude de suas deficiências; Lei no 13.146 - Lei brasileira de inclusão da pessoa com deficiência (LBI): o capítulo IV aborda o direito à educação, com base na Convenção sobre os direitos das pessoas com deficiência, que deve ser inclusiva e de qualidade em todos os níveis de ensino; garantir condições de acesso, permanência, participação e aprendizagem, por meio da oferta de serviços e recursos de acessibilidade que eliminem as barreiras (MEC, 2009).

O AEE também está contemplado, entre outras medidas. Ampliou muito o desenvolvimento da linguagem, escrita, socialização, inovação de ideias, porque foi trabalhado com os materiais concretos. Assim, o ensino deixa de ser tradicional, de forma assistencialista, onde o professor da antiguidade participava no trabalho colaborativo em sala de aula somente em observações das aulas, fazendo registros dos estudos realizados no ensino regular, as provas não eram adaptadas às necessidades educacionais dos alunos, as metodologias, as atividades também não eram adaptadas, conforme determina a LDB/96 Art. 59. Entretanto, esta unidade de ensino tem procurado desenvolver os conteúdos consoantes às leis inclusivas, os aprendizes confeccionam os materiais concretos conforme suas habilidades.

Dessa forma eles confeccionaram diversos objetos, dentre eles: 1. Uma seladora de sacola plástica com o uso da corda de violão e um motor de micro-ondas que estava em desuso; 2 . Um cortador de isopor 
utilizando o motor de micro-ondas; 3. As luminárias de bambu, os alunos confeccionaram aqui na escola, pintaram com o verniz, utilizaram o barbante para fazer o acabamento; 4. Ralador de coco utilizando o motor de tanquinho; 5. Um monjolo de bambu simbolizando o trabalho árduo antigo; 6. Um aspirador de pó com dupla função de assoprar e soprar as poeiras com motor de liquidificador; 7. Uma máquina de cortar madeira, utilizando motor de tanquinho; 8. Um escovador de chão para pisos com motor antigo de máquina de lavar roupas; 9. Um jogo denominado de Computer game com tradução para o português e sinalização feita pelos alunos, o circuito elétrico, as ligações e inovações de sinalizações foi confeccionado pelo aluno da $2 \underline{a}$ série do Ensino Médio, os acabamentos pelos alunos do 70 ano Ensino Fundamental, utilizando buzina de carro, lâmpadas para o painel. Todos os trabalhos realizados acima foram confeccionados pelos próprios alunos direcionados pelo Gestor, Pedagoga, professora do AEE e alguns professores do Ensino regular. Ainda existem professores que possuem a resistência com o ensino inclusivo, todavia nesta escola o trabalho inclusivo tem avançado, a atual Direção da escola tem oportunizado a sala do AEE a expor às leis da inclusão e junto com a pedagoga cobram um ensino adaptado às necessidades educacionais dos alunos especiais.

Os estudantes Escola Estadual de Ensino Fundamental e Médio (EEEFM) José Teixeira Fialho público alvo da Educação Especial obtiveram medalhas de 'Menção Honrosa' pela participação na 25a Mostra Brasileira de Foguetes (MOBFOG). O evento foi realizado entre os dias 12 e 15 de novembro de 2019, em Barra do Piraí, no Rio de Janeiro. O projeto foi desenvolvido pelos estudantes, que construiu sua própria base de foguetes; construtores dos foguetes de garrafa PET. Eles foram orientados pela professora do Atendimento Educacional Especializado (AEE), Renilza Falquete Cardoso, que acompanhou os alunos na Mostra; e pelo diretor Jailson Maurício Pinto.

A atividade, seguiu as diretrizes da Base Nacional Comum Curricular (BNCC), do Currículo do Estado do Espírito Santo, que enfatiza o protagonismo nas escolas, o trabalho da equidade, inclusão, contemporaneidade e desenvolvimento das tecnologias, utilizando recursos para facilitar a aprendizagem dos estudantes. Os estudantes especiais têm habilidades notáveis e que merecem ser desenvolvidas, expandindo seus conhecimentos e trazendo avanços para a Educação em todos os níveis e etapas de ensino. A gestão da escola, na pessoa do diretor, Jailson Maurício Pinto, incentiva bastante a participação dos alunos em projetos escolares trazendo equidade para o campo escolar.

O protótipo também foi apresentado na II Mostra Estadual de Astronomia, Astrofísica, Astronáutica e Cosmologia da Universidade Federal do Espírito Santo (UFES), Campus São Mateus, no dia 07 de novembro de 2019.

Os alunos que fazem parte do 'Projeto Tecnologia e Inclusão na Prática', da Escola Estadual de Ensino Fundamental e Médio (EEFM) José Teixeira Fialho, de Ecoporanga, apresentaram um protótipo de foguete feito de garrafas PET na II Mostra Estadual de Astronomia, Astrofísica, Astronáutica e Cosmologia da Universidade Federal do Espírito Santo (Ufes), campos São Mateus, oportunizando estudantes e professores o contato com outros estudantes do Estado. 


\section{RESULTADOS E DISCUSSÃO}

De acordo com os indicadores de produtividade Institucional, podemos ver que as ações realizadas na escola surtiram efeito positivo tanto nas ações qualitativas como demonstrado anteriormente por meio dos projetos de ensino desenvolvido na Instituição, bem como pela análise quantitativa, conforme podemos analisar abaixo os resultados de fluxo por ano letivo. Percebe-se que a cada ano a escola teve avanço no desempenho escolar. Quando a gestão escolar incentiva a equipe escolar a abraçar uma ideia ou uma ação, os resultados são representados em ações. Tanto qualitativas quanto quantitativas.

Quadro 1: Análise quantitativa dos resultados de fluxo por ano letivo.

\begin{tabular}{|l|l|l|l|l|l|l|}
\hline & Matrículas & Aprovação & Reprovação & Evasão & Transferência & $\begin{array}{l}\text { Aproveitamento } \\
\text { Total \% }\end{array}$ \\
\hline 2014 & 255 & 201 & 54 & 18 & 24 & $78,8 \%$ \\
\hline 2015 & 235 & 202 & 33 & 15 & 24 & $85,9 \%$ \\
\hline 2016 & 212 & 187 & 25 & 3 & 46 & $88,2 \%$ \\
\hline 2017 & 206 & 203 & 3 & 0 & 21 & $98,5 \%$ \\
\hline 2018 & 197 & 188 & 09 & 2 & 49 & $95,43 \%$ \\
\hline 2019 & 193 & 184 & 00 & 00 & 09 & $100 \%$ \\
\hline
\end{tabular}

Após análise dos resultados obtidos fica nítido a necessidade da interação do diretor escolar junto ao pedagogo e equipe pedagógica em busca de melhores resultados de aprendizagens. A Educação Especial não pode ser vista como algo a mais na educação, mas ser vista como uma oportunidade de aprendizagem e de mudanças de paradigmas em busca de uma educação que seja equitativa e que busca tratar o ser humano com mais humanismo. Tratando cada pessoa como ser único que merece respeito e de atitudes cidadãs em busca de um atendimento que valorize cada ser.

\section{CONCLUSÕES}

Partindo do pressuposto da escola se tornar cada vez mais inclusiva, é necessária adaptação para receber os estudantes da forma que são, porque toda a criança e adolescente tem direito à educação, visando ao pleno desenvolvimento de sua pessoa, preparo para o exercício da cidadania e qualificação para o trabalho. Diante disso, é preciso garantirmos uma educação que tenha esse viés que trabalhe com a diversidade encontrada propondo um atendimento que visa a equidade.

Qualquer política de inclusão precisa estar firmemente embasada na suposição inicial de que todas as crianças devem ser educadas em escolas regulares. Deve-se reconhecer que os obstáculos à inclusão estão na escola e na sociedade, e não na criança.

Muitos projetos trazem como justificativa a inclusão social, porém relatam atividades isoladas em classe ou escola especial. Alguns colocam o conhecimento da deficiência como conteúdo, sem proporcionar aos alunos a convivência. Mesmo assim, percebe-se um esforço dos educadores para diminuir o enfoque clínico e de reabilitação.

Sabe-se que na proposta educacional inclusiva o currículo deve ser pautado a ideia da diferença e não é o aluno que se ajusta, se adapta as condições de ensino, mas a leitura do movimento da inclusão 
educacional é exatamente o oposto, é a equipe escolar que tem que prover as mudanças necessárias para que o aluno consiga acessar o currículo. Em tempos outrora era o aluno que deveria adequar a escola, atualmente é a escola que deve se adaptar ao aluno para que este esteja motivado a estudar, permanecer na unidade.

Assim, verificamos que antigamente na escola era imposto como o aluno deveria se adequar para ser atendido, atualmente é a escola que deve se organizar na melhor maneira para atender esses alunos especiais oferecendo oportunidades para que o mesmo desenvolva suas habilidades, traçar estratégias de ensinos, observando atentamente as leis vigentes da inclusão a fim de que promovam a permanência e o sucesso do processo de ensino aprendizagem destes no âmbito escolar.

\section{REFERÊNCIAS}

CECCON, M. C.; OLIVEIRA, R. D.. A vida na escola e a escola da vida. 33 ed. Petrópolis: Vozes, 1998.

CHABANNE, J.-L.. Dificuldades de aprendizagem: um enfoque inovado do ensino escolar. São Paulo: Ática, 2006.

ESTEBAN, M. T.. Avaliação: uma prática em busca de novos sentidos. 5 ed. Rio de Janeiro: DP\&A, 2003.

FERRAÇO, C. E.. Cotidiano escolar, formação de professores (as) e currículo. 2 ed. São Paulo: Cortez, 2008.

GARCIA, R. L.. A avaliação e suas implicações no fracasso/sucesso. In ESTEBAN, M. T.. A avaliação: uma prática em busca de novos sentidos. 5 ed. Rio de Janeiro: DP\&A, 2003.
GRACIANI, M. S. S.. Pedagogia social de rua: Análise e sistematização de uma experiência vivida. 4 ed. São Paulo: Cortez, 2001.

MEC. Ministério da Educação. Resolução n. 4, de 2 de outubro de 2009. Institui diretrizes operacionais para o atendimento educacional especializado na educação básica, modalidade educação especial. Brasília: MEC, 2009.

PERRENOUD, P.. A pedagogia na escola das diferenças. 2 ed. Porto alegre: ARTMED, 2001.

SCHAIN, R. J.. Distúrbios de aprendizagem na criança. São Paulo: Manole, 2002.

A CBPC - Companhia Brasileira de Produção Científica (CNPJ: 11.221.422/0001-03) detém os direitos materiais desta publicação. Os direitos referem-se à publicação do trabalho em qualquer parte do mundo, incluindo os direitos às renovações, expansões e disseminações da contribuição, bem como outros direitos subsidiários. Todos os trabalhos publicados eletronicamente poderão posteriormente ser publicados em coletâneas impressas sob coordenação da Sapientiae Publishing, da Companhia Brasileira de Produção Científica e seus parceiros autorizados. Os (as) autores (as) preservam os direitos autorais, mas não têm permissão para a publicação da contribuição em outro meio, impresso ou digital, em português ou em tradução. 